City University of New York (CUNY) CUNY Academic Works

\title{
An Ode to James Van Der Zee: Lorna Simpson's 9 Props
}

Emilie C. Boone

CUNY New York City College of Technology

\section{How does access to this work benefit you? Let us know!}

More information about this work at: https://academicworks.cuny.edu/ny_pubs/684

Discover additional works at: https://academicworks.cuny.edu

This work is made publicly available by the City University of New York (CUNY).

Contact: AcademicWorks@cuny.edu 


\section{An Ode to James Van Der Zee: Lorna Simpson's 9 Props}

\section{EMILIE BOONE}

Fifty years ago, The Metropolitan Museum of Art acquired the largest collection to date in a public institution of works by the African American photographer James Van Der Zee. The acquisition of sixty-six photographs in 1970, and an additional four in 1971, arrived on the heels of the Museum's 1969 exhibition “'Harlem on My Mind': Cultural Capital of Black America, 1900-1968," a controversial show considered today by many scholars as a pivotal moment in the exposure of Van Der Zee's oeuvre to the greater public. ${ }^{1}$ In the mid-1990s, the artist Lorna Simpson turned to Van Der Zee and his studio portraits as source material for 9 Props, an edition of which came to the Metropolitan Museum in 1998 (fig. 1). 9 Props is often interpreted in relation to portraiture, but recent scholarship suggests more nuanced readings of what Simpson

fig. 1 Lorna Simpson (American, b. 1960). 9 Props, 1995. Waterless lithograph on wool felt panel, 9 panels, each $14 \frac{1}{4} \times 101 / 4 \mathrm{in}$. (36.2 $\times$ $26 \mathrm{~cm}$ ). The Metropolitan Museum of Art, Gift of the Peter Norton Family Foundation, 1998 (1998.456.5a-j) 

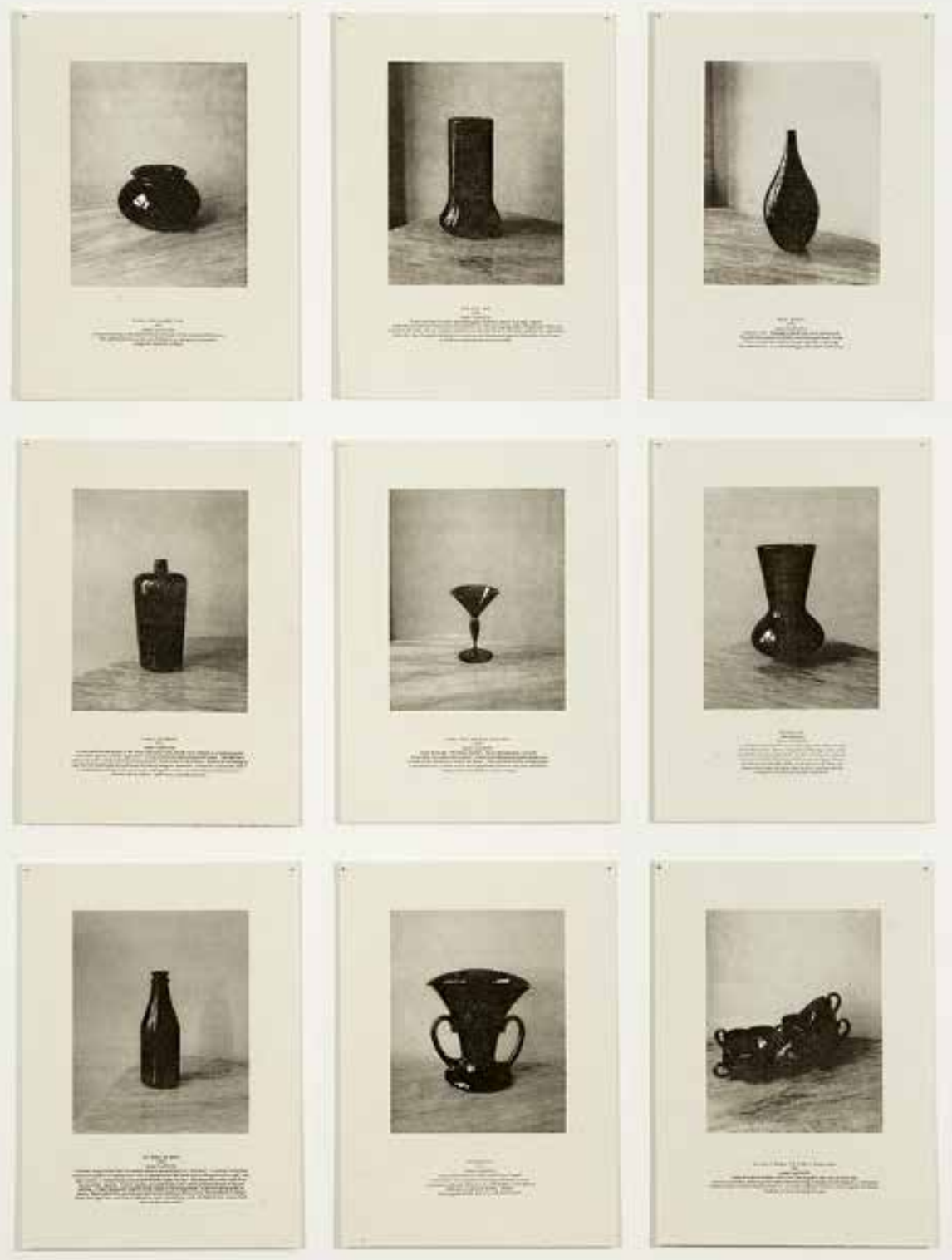
has described as an homage to Van Der Zee. ${ }^{2}$ If 9 Props is "a close study of Van Der Zee's photographs at a remove,"3 what kind of interpretative framework is Simpson offering not only for her own work but also for Van Der Zee's images?

As a genre, portraiture has a clear set of norms: it depicts individuals while suggesting a time, place, and set of character traits through intentional positioning, props, and settings. In the Van Der Zee photographs referenced in 9 Props, the subject is often in the center of the composition, looking toward the viewer, and the background and other details symbolically imply aspects of the individual's social standing and character. For the art historian Shawn Michelle Smith, 9 Props reframes the aspirational politics of early twentiethcentury Harlem by offering each subject the possibility of new imaginings, free from historically contingent assumptions about gender, sexuality, and class mobility. ${ }^{4}$ As a departure from gifting the portrait's subject with new outlets of becoming, this article privileges the viewer. ${ }^{5}$ The importance of Van Der Zee's photographs lies less with the individuals he captured and more with the material and aesthetic decisions he made in service to the viewer's experience of looking. Building off the philosopher Vilém Flusser's statement that "photographers, it is true, do not work but [...] they create, process and store symbols," one can begin to unpack how Simpson's project recasts the symbols that Van Der Zee has stored in his images, ${ }^{6}$ and the prop, as the art historian Sara Blair has suggested, becomes an intriguing point of entry for understanding 9 Props as an ode to Van Der Zee's work.

Much of the writing on photographs of African Americans concerns how Black subjects image and imagine themselves, and 9 Props, in part, depends upon the ways in which a prop, at its most basic level, requires the viewer to construct a scene or story. ${ }^{8}$ Recognizing how Simpson took her cue from Van Der Zee and the narrative woven around his work and life enables the viewer to use the concept of a "prop," through its various definitions, as a central platform of engagement, one that compels them to find and create meaning in the ordinary through a sense of imagination. Examining Simpson's motivations and processes for making fig. 2 Lorna Simpson. Waterbearer, 1986. Gelatin silver print with vinyl lettering, $59 \times 80 \times 2 \frac{1}{4} \mathrm{in}$. $(149.9 \times 203.2 \times 5.7 \mathrm{~cm})$ Private collection

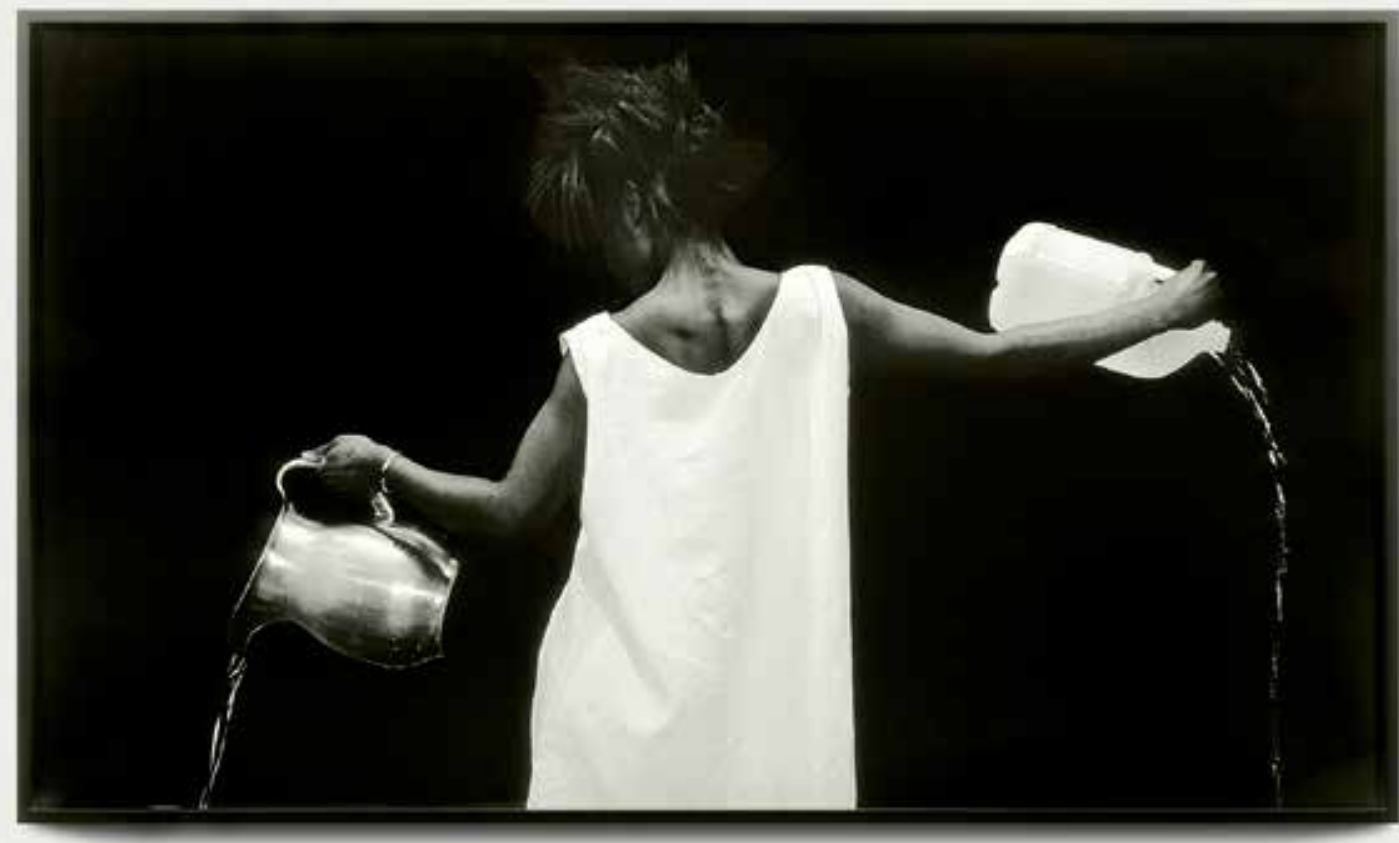

\section{SHE SAW HIM DISAPPEAR BY THE RIVER, THEY ASKED HER TO TELL WHAT HAPPENED, ONLY TO DISCOUNT HER MEMORY.}


9 Props opens up a more expansive reading of Van Der Zee's imagery, presenting an interpretative framework not only for deciphering her own work and its evocation of absence and touch, but also for accessing the photographs of Van Der Zee. 9 Props hinges upon Van Der Zee's portraits in ways that illustrate how parallel readings of the works can bring an intrinsic relationship between imagination and African American photography into view. ${ }^{9}$

\section{AN HOMAGE}

Referred to as a photo-text project, Simpson's 9 Props is a portfolio of nine waterless lithographs printed on wool felt panels that are exhibited in a grid. ${ }^{10}$ This type of offset lithography, also known as siligraphy, uses a water-repellent silicone plate. ${ }^{11}$ Different from traditional lithography, in which moisture resists ink, siligraphy operates on the basic principle that ink does not stick to silicone rubber. Each panel contains a highly saturated black-and-white photographic print that depicts a piece of glassware, positioned on a table in front of a nondescript background. These objects are based on vases, goblets, martini glasses, and other props culled from nine Van Der Zee photographs, the majority of which were taken in the early twentieth century. ${ }^{12}$ Centered underneath each image is a text detailing the title and date of the source photograph, followed by Van Der Zee's name and a description of the Van Der Zee photograph to which the panel refers.

The glassware in 9 Props was created during Simpson's 1994 artist residency at Pilchuck Glass
School in Stanwood, Washington. Simpson had initially intended to use her residency to construct an installation of vibrating glass objects, but that preliminary idea lost its appeal once she understood more about the culture of glass and became captivated by the theatricality of glassblowing. ${ }^{13}$ While searching for a new direction, Simpson took a trip to Seattle, where she found and purchased a book that she already had at home, the catalogue for the National Portrait Gallery's 1993 Van Der Zee exhibition, which helped to inspire aspects of the larger conceptualization of what would become 9 Props. ${ }^{14}$ To the chagrin of the ambitious gaffers assigned to assist Simpson, she requested that they simply blow replicas of Van Der Zee's props, ${ }^{15}$ and in the end, William Morris and Dante Marioni produced a number of large, smooth black-glass vessels. ${ }^{16}$ After the residency concluded, Simpson shipped the pieces to her New York studio, where she photographed them. She later sent the images to 21 Steps in Portland, Oregon, where they were handprinted on wool felt, a material with distinct tactile properties resulting from its compressed but visible fibers. ${ }^{17}$

From a photograph of Simpson taken during her time at Pilchuck (see fig. 4), it is evident that she requested the creation of glass objects that do not appear in 9 Props, one of which resembles the pitcher from her 1986 photograph Waterbearer (fig. 2).

Additionally, the sheets of paper with cutout shapes and sketches tacked on the wall behind the artist provide clues to the intermediary steps involved in the translation of the props from the Van Der Zee photographs reproduced in the catalogue to the blown glassware,

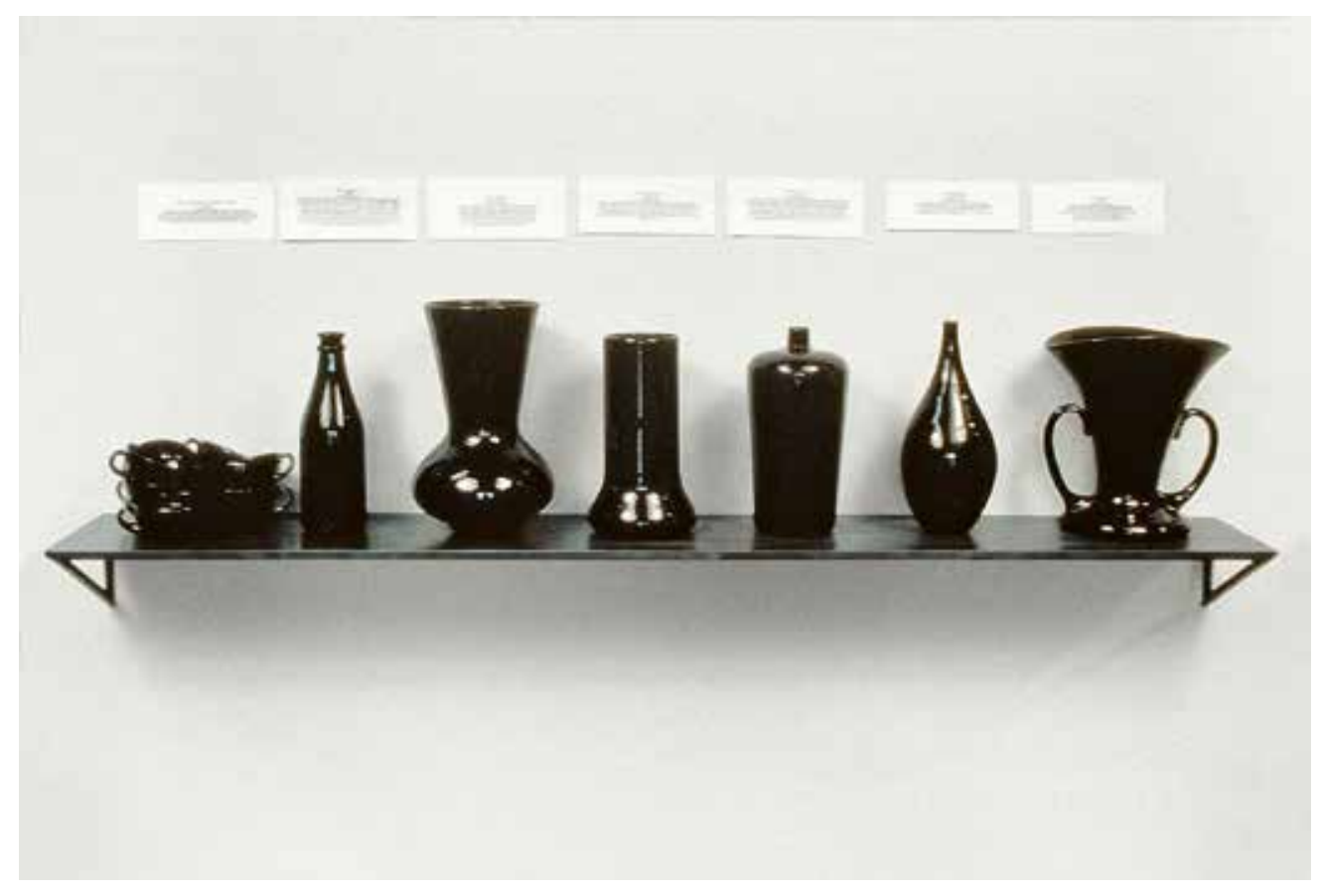


fig. 4 Lorna Simpson during artist residency at Pilchuck Glass School, Stanwood Washington, 1994

fig. 5 James Van Der Zee (American, 1886-1983). Jean-Michel Basquiat 1982. Gelatin silver print. Collection of Donna Mussenden Van Der Zee

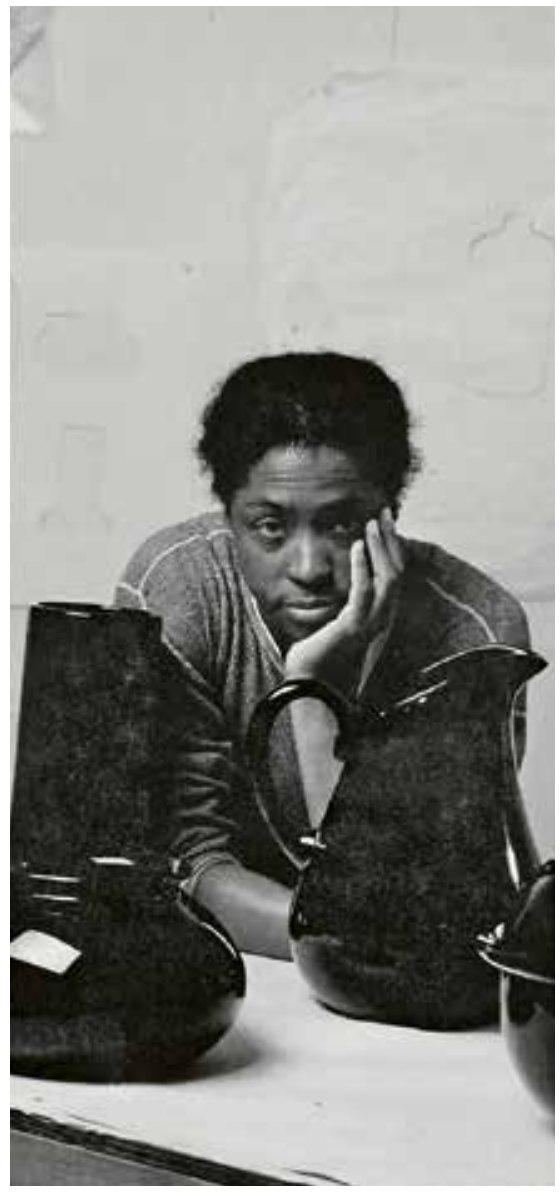

suggesting that Simpson first recreated the vessels as basic linear shapes. Simpson also used some of the glassware from Pilchuck in two visually familial works that came before 9 Props. In the first, VanDerZee Props (1994), black blown-glass vessels are arranged on a steel shelf with corresponding text above each of the objects (fig. 3). In the second, Van Der Zee Prop Vase (1994), a photolithograph print on paper with text, the same vase later employed in the 9 Props panel "Reclining nude" appears, although shot from a different angle. ${ }^{18}$ As forerunners to 9 Props, the vessels arranged on a shelf and the photolithograph establish a lineage of similar reoccurring forms.

Intriguingly, Simpson's artistic process for 9 Props alludes to a kind of repetition with an intentional difference in which she never loses sight of the work's referential origin and her initial interest in Van Der Zee's work. As the artist later explained, she "re-photographed these [the glass vessels] as a kind of homage to James Van Der Zee." ${ }^{19}$ By "re-photographing" as opposed to "photographing," Simpson demonstrates a sustained engagement with the original images as props for her own work. ${ }^{20}$ As an artist would use a camera obscura, Simpson employs technology to trace all the contours and tones of the vessels in the meticulous settings of

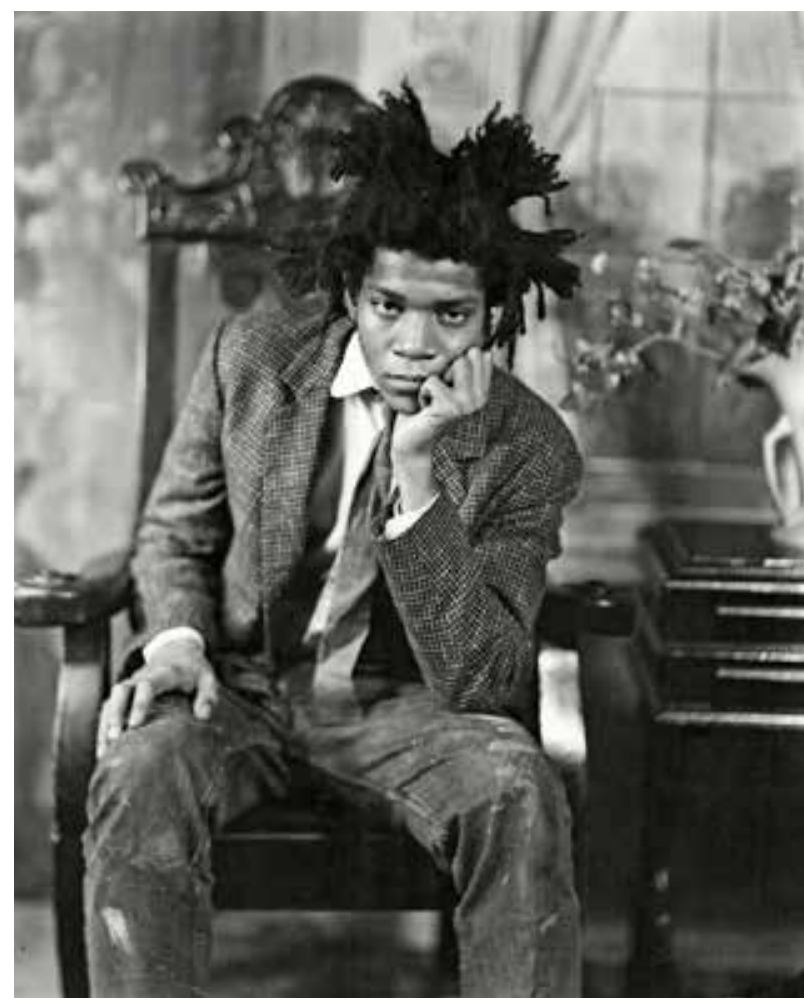

Van Der Zee's portraits and translates them into a new medium, selecting and changing details along the way. From a staged studio to a photograph to a glass object and back to a photograph, each prop is reworked again and again through time, material, and space. On another level, this reiterative process parallels Van Der Zee's own expansive engagement with the craft of photography. For example, Van Der Zee would choreograph highly composed portraits, develop a range of prints, and then enhance these images with hand-coloring or superimpose the same image with another. At each stage, he would thus often build upon the previous one to transform the image into a new iteration.

The nine photographs Simpson selected as source material for 9 Props are a mere fraction of the tens of thousands taken and often printed in multiples by Van Der Zee, whose career began in 1911 when he started as a darkroom technician at Hahne \& Company department store in Newark, New Jersey. About five years later, he opened his first photography studio on 135th Street in Harlem within the neighborhood's liveliest area. ${ }^{21}$ His dynamic output includes studio and on-site portraits, street scenes, mortuary photographs, reprints, enlargements, and prints enhanced by handwork. Throughout the 1920 s and 1930s in particular, Van Der Zee 
produced a number of skillfully composed portraits that feature props, ranging from domestic items, such as chairs, side tables, and rugs, to scenic painted backdrops and even a paper cutout of a seated dog. ${ }^{22}$ Although he took a hiatus after closing his last studio in 1969, Van Der Zee later returned to photography during the last years of his life. In these portraits of well-known African Americans, the veteran photographer incorporated many of the very same props that he had used decades previously to craft his aesthetic vision. Retrieved from storage, the old studio props were dusted off, mended up, or in the case of the backdrops, recreated, in order to fulfill a new role within nostalgic compositions. ${ }^{23}$

\section{THE PROP}

As a noun, "prop" refers to a beam or pole used to keep an object in position or something that serves as a source of assistance or support. ${ }^{24}$ As a verb, it most commonly means to position something for support, but it can also be used colloquially to recognize influence and convey respect-namely, "to give props." In the same decade that Simpson made 9 Props, this colloquial usage was starting to become popular in hip-hop prose when acknowledging the importance of one's predecessors. ${ }^{25}$ While Van Der Zee received increasing recognition after his inclusion in "Harlem on My Mind," with a solo exhibition in 1970 at the Lenox Public Library in Massachusetts, a PBS documentary devoted to his career in 1977 and an appearance on the Dick Cavett Show in 1978, and honorary degrees from Seton Hall University in 1976 and Howard University in 1983, the early appreciation of his work was most often confined to its documentary value within the cultural climate of Harlem, separated from other art world discourses.

In part, Simpson attempts to address this exclusion through 9 Props. As she explains in an interview published in 1996:

\footnotetext{
To me, Nine Props [sic] has historical content. For instance, many people within the art world don't even know who James Van Der Zee is. Not that [9 Props] position[s] his work in a way that allows a lot of information to be gleaned, but on a certain level it's engaging a part of art history that does not seem of interest to the contemporary art world. The academy's canon has nothing to do with James Van Der Zee. ${ }^{26}$
}

Simpson recognizes Van Der Zee through 9 Props, but more importantly, she moves Van Der Zee into the contemporary art sphere. By using his photographs as a primary source, 9 Props does the work of a traditional prop-it supports and sustains. In this case, it does so within a context that transcends the particular time period listed within each panel of 9 Props and prompts the viewer to consider Van Der Zee's applicability to contemporary artistic production. A cadre of Black cultural producers, including the author Toni Morrison, the filmmaker Julie Dash, and the artist Isaac Julien, have cited the impact of Van Der Zee on their work, evidence that the photographer has gained a somewhat silent foothold throughout various instances of Black cultural production. ${ }^{27}$ Such artistic engagements across time and medium often begin with an encounter and result in a nod of recognition, like that of Jean-Michel Basquiat painting a portrait of the aging Van Der Zee after the photographer took a formal studio portrait of the younger artist (fig. 5). ${ }^{28}$ Each of these instances supports and sustains innovative engagements with Van Der Zee's photographs that can reframe how his work is considered.

Moreover, Simpson gives "props" to Van Der Zee by privileging the visual details of his images in her descriptive texts. In "A man in his bedroom," the scene is presented cinematically:

\footnotetext{
A man stands on the far left of the room with a pipe in his mouth. He is dressed in a smoking jacket with a shirt and tie, with his right elbow resting on a dresser and a ring on his finger. The bed has a satin cover with a small stuffed animal positioned at the center of the pillows. Behind the bed hangs a rug, off of the backboard a fringed lamp, and above hangs a chandelier. In front of a curtained window a standing lamp shines on the portrait of a full figured woman. On the right side of the room is a dresser with an ashtray, small boxes, and a candle and vase.
}

With few exceptions, the text in each of the nine panels progresses in a way that begins with the person within the portrait and concludes with a mention of the specific prop that Simpson recreated and re-photographed, thus delaying the viewer's ability to locate that prop within the described scene. Simpson asks the viewer to conjure or imagine Van Der Zee's compositions first, even though the prop is the sole object depicted within the panel.

In discussing the general role of text, curator Okwui Enwezor articulates its relationship with historiography. He writes:

\footnotetext{
If history is text and its interpretation is anchored in reading (a debate prevalent in semiotic studies) Simpson's work seems to recover the patterns of its writing. Her
} 
work seems to insist that it is those who possess the power of speech who not only narrate history but determine its outcome. In her work the hitherto disempowered subject reclaims this primal function of historiography, to tell the story from her own unique experiences, recollections and perspectives, to inscribe and assert her subjectivity, to recover both popular and private memories. ${ }^{29}$

Although Enwezor puts the onus on the disempowered subject as the one responsible for shifting the possibilities of interpretation, it is more appropriate with 9 Props to give this august role to the viewer. With Simpson's text leading the way, the viewer is able to imagine a different approach to Van Der Zee's work, thereby contributing to an expanded historiography.

While Van Der Zee and his work have been interpreted within an art historical framework that privileges neat time periods, artistic movements, and a singular talented artist, 9 Props enables a rethinking of Van Der Zee's impact and therefore presents an amendment to the narrative that illuminates his work. If 9 Props, as curator Jontyle Theresa Robinson posits, serves as a witness to Van Der Zee's sixty years of history, then this history can be imagined differently. ${ }^{30}$ Though Simpson notes that 9 Props has "historical content," her project eschews a chronological presentation of Van Der Zee's oeuvre. In fact, the display of the nine identically sized panels in a neat rectangle visually reinforces a sense of timeless uniformity. ${ }^{31}$ Furthermore, the date of the source photograph is largely irrelevant to the structure of the piece, as a panel with the year 1926 is positioned next to a panel with the year 1976, a detail discernible only from the descriptive texts. Here, historical readings are discouraged, despite the historical context from which Simpson draws, and the viewer can recreate each portrait personally with little regard to the specificity of each image's time period. ${ }^{32}$

Simpson's approach to Van Der Zee's work was also arguably informed by interpretations offered in the exhibition catalogue she bought in Seattle. In her essay "They Knew Their Names," the photography historian Deborah Willis provides an overview of the significance and aesthetic value of Van Der Zee's photographs. Importantly, she discourages a reading of Van Der Zee as "a neutral observer of his times," and as a photographer who produced "a visual record of the emergence in America of the African American middle and upper classes"; 33 instead, she frames Van Der Zee as an innovative artist and one of the creators of the Harlem Renaissance's visual culture. Similarly, by omitting the language of respectability and upward mobility in the descriptive texts, Simpson allows Van Der Zee's photographs to be seen as a generative site of meaning as opposed to a reinforcement or confirmation of an accepted historical narrative built on classbased racial progress. Simpson's approach to Van Der Zee's work lingers on the visual elements of his photographs as opposed to being tethered to preconceived understandings of his work that tend to structure their interpretation.

Additionally, in 9 Props Simpson has made central and beautiful that which is most often marginal or, fig. 6 Lorna Simpson. Detai of 1957-2009 Interior, from May June July August, '57/'09, 2009
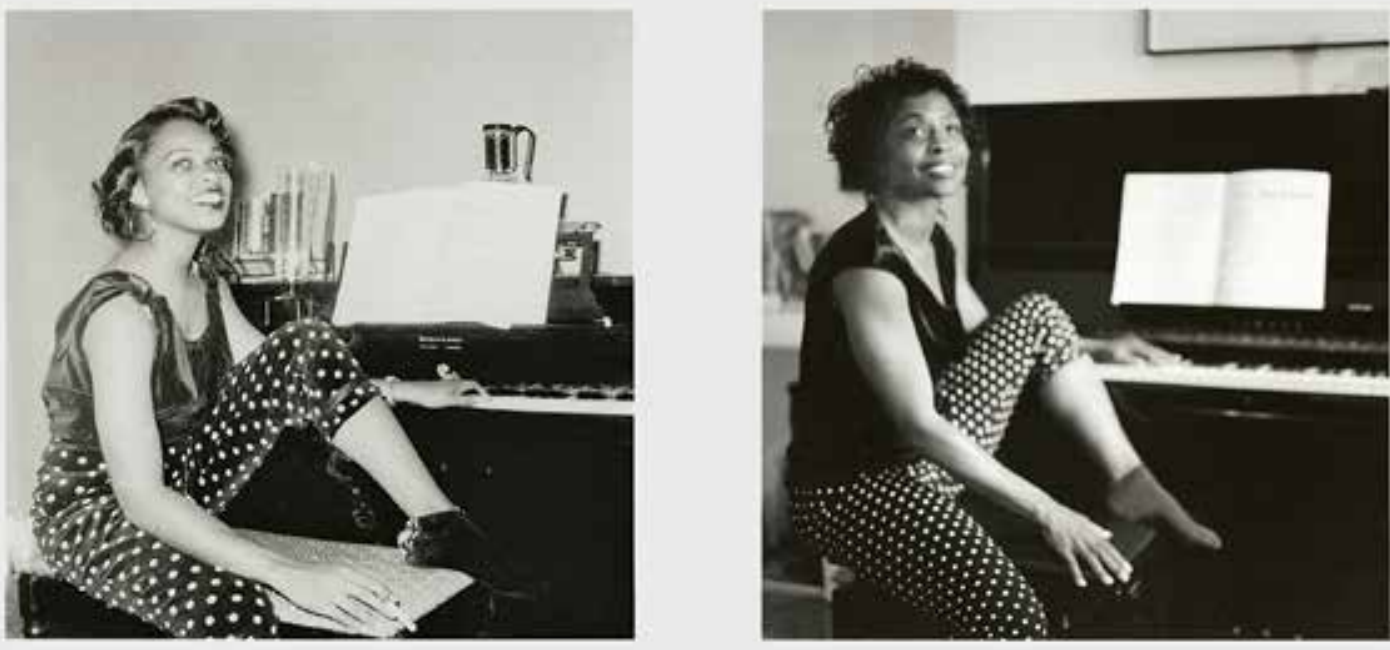
fig. 7 James Van Der Zee. Woman with a Goldfish Bowl, 1923. Gelatin silver print

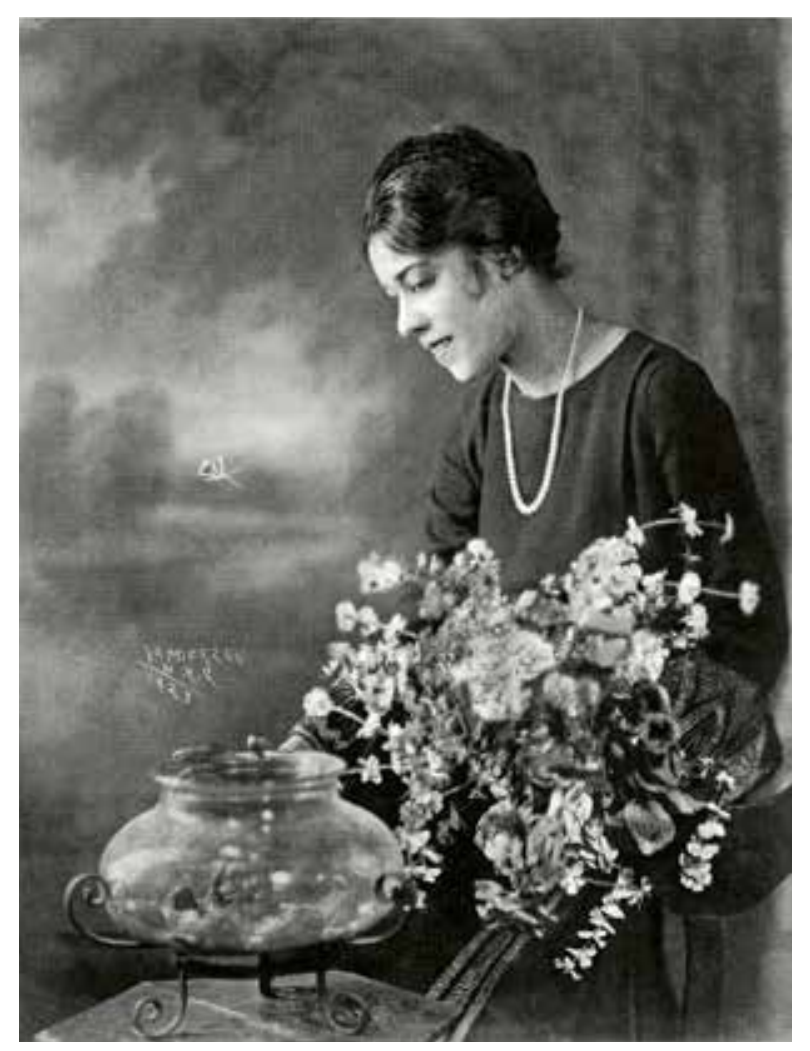

within the context of the nineteenth century, invisible and cumbersome. As a creator of ideas that have conceptual weight, Simpson contributes to an enduring conversation on props that has pivoted in various directions. ${ }^{34}$ When considering the purpose of the headrest, a common prop in nineteenth-century photography studios, the theorist and philosopher Roland Barthes in Camera Lucida states, "a device was invented, a kind of prosthesis invisible to the lens, which supported and maintained the body in its passage to immobility: this headrest was the pedestal of the statue I would become, the corset of my imaginary essence. ${ }^{{ }^{35}}$ For Barthes a prop stills, inhibits, and stifles-it is the antithesis of a support. In his 1931 essay "Little History of Photography," the philosopher Walter Benjamin writes of props in a similarly charged and exasperated tone; they no longer fade into the background but instead play an uncanny role. He comments on what he calls the "nonsense" of the studio setting, explaining that " $[t]$ his was the period of those studios-with their draperies and palm trees, their tapestries and easelswhich occupied so ambiguous a place between execution and representation, between torture chamber and throne room. ${ }^{36}$ Whether squeezing one's "imaginary essence" or occupying an unsettlingly ambiguous place, the prop in studio photography is more than a mere object, it is a player in a staged performance, stilled by the lens shutter.
By moving the prop from a marginal position to center stage, Simpson translates Van Der Zee's works on two levels. The first shift is from vernacular culture to high culture: photographs once displayed on clients' home mantels, in store-bought frames or wedding albums, are transformed into contemporary works of art with white frames. The second shift speaks to Barthes's and Benjamin's interest in turning the prop into something less ordinary. In Simpson's hands, the prop is not a stifling and liminal device but an appealing conceptual outlet for the viewer. Simpson gives the viewer permission to imagine the possibilities of Van Der Zee's photographs by interpreting the mundane as a valuable tool of cultural work and a means for imaginative reflection.

\section{FOUND OBJECTS, ABSENCE, AND TOUCH}

Simpson started to incorporate found objects in her work about the time she made 9 Props. One notable example is her mixed-media sound installation Hypothetical?, from 1992, which features instrumental mouthpieces, discovered at a local thrift store, in addition to a newspaper clipping and photographs. The 2011 exhibition "Lorna Simpson: Gathered" at the Brooklyn Museum presented hundreds of original and found vintage photographs of individuals of African descent, sourced by the artist from eBay, flea markets, and thrift stores. Simpson's practice of collecting and recontextualizing vernacular photographs in particular, many of which share social functions similar to those of Van Der Zee's work, illustrates an ongoing interest in finding new outlets of meaning through old, everyday photographs.

In the later work 1957-2009 Interior (2009), which was included in the 2011 exhibition, Simpson juxtaposes found images of a young African American woman with portraits of herself replicating the poses and settings of the original photographs (fig. 6). Her staged response creates a "fictionalized narrative in which the two characters appear to be linked across history in a shared identity or destiny. ${ }^{37}$ Here, the sideby-side arrangement invites the viewer to compare and contrast what at first glance appear to be identical images. Yet, upon closer inspection, the images slowly reveal themselves as different. Certain props in the found photograph-like the cigarette in the woman's hand, or the vases behind the piano in the image on the left in figure 6-are omitted in the recreated scenes featuring Simpson.

Though absence is central to both 1957-2009 Interior and 9 Props, the former relies primarily on sight, while the latter withholds visual clues. In "Woman with 
a goldfish bowl," the text invites the viewer to notice the absence of the woman, the butterfly she gazes at, and other details found in Van Der Zee's photograph (fig. 7). Here, Simpson uses the juxtaposition of text and image to draw attention to incompleteness while bringing into focus the role of imagination. The incompleteness of 9 Props is even suggested by its title-a prop is an object that enhances or supports another object, but only one object is depicted. She continues this theme of absence in the image, in which the viewer sees a bowl, the table on which it is placed, and an atmospheric background. Although the panels convey a sense of timeless uniformity, each of the vessels has a different position on the table: some are on corners, some appear to be closer to the center. While the actual panels fit into a neat rectangular grid, the table within each of the images does not linearly correspond to the following table. Instead, the discontinuities highlight the fragmentary nature of the project, which encourages the viewer to be transported somewhere else. ${ }^{38}$

Yet, as much as 9 Props encourages imaginative leaps divorced from a specific time period, the work itself came about within a very particular historical context. The art world changed dramatically in the 1990s. Often defined by the watershed 1993 Whitney Biennial, the decade is memorialized in art history for pushing

fig. 8 James Van Der Zee Flapper in Beaded Headdress, 1925. Gelatin silver print and mirror, $23 / 4 \times$ $13 / 4$ in. $(7 \times 4.5 \mathrm{~cm})$. The Metropolitan Museum of Art, Gift of the artist, 1971 (1971.533.3) gender, race, sexuality, and other topics relating to identity to the forefront of artistic practices and criticism in ways that still resonate years later. Additionally, the Biennial facilitated a kind of conversation that appealed to both enthusiastic museum visitors and an expanded audience drawn from a wider social sphere. ${ }^{39}$ Shifts in museum acquisition and exhibition practices also gave women and artists of color opportunities for exposure in the art world. ${ }^{40}$

The 1990 s were pivotal years in Simpson's artistic development. By 1995, she had completely stopped creating three-dimensional installations and had begun to focus almost exclusively on photographic impressions printed on wool felt-her new preferred material. ${ }^{41}$ Felt first appears in Simpson's work in 1994, when, in her own words, she "decided to investigate the surface." ${ }^{42}$ This "turn to felt," as the art historian Kellie Jones calls it, is often interpreted as a platform for addressing sensuality and tactility, and these issues are key to 9 Props. ${ }^{43}$

In 9 Props the thickness of the felt gives the panels dimension while the visible fibers suggestively trigger the viewer's desire to touch the textured surface. Similarly, within Van Der Zee's oeuvre, photographs function intrinsically through their materiality. Through one's imagination, to pick up, pin, and notice the oval frames of the four Van Der Zee lapel buttons found within the Metropolitan Museum's collection is to foreground their tactility (see fig. 8). In parallel ways, Van Der Zee's photograph Woman with a Goldfish Bowl and the corresponding panel in 9 Props both call attention to touch. Van Der Zee altered the physical surface of the original photograph by hand, meticulously etching or painting the butterfly, enhancing the delicate lines around the woman's facial features, and handcoloring the bouquet. The text in the corresponding panel also specifically mentions the "painted" butterfly and notes that the woman's hand "rests on the rim of the bowl," prompting the viewer to imagine the artist's hand as well as the feel of the glass bowl. 9 Props asks viewers to reframe the tactility of Van Der Zee's photographs as a driving force of interpretation. Doing so supports a different approach to his work than existing histories have afforded.

\section{THE NUDE}

During the 1990s, a second shift occurred in Simpson's art-the figure disappeared. ${ }^{44}$ Having established her reputation through evocative depictions of the Black female form, Simpson made a marked change with what has come to be known as the "bye, bye black girl" moment. ${ }^{45}$ In her felt works, Simpson often focuses on 
fig. 9 James Van Der Zee. Reclining Nude, 1920s-40s. Gelatin silver print with applied color, $7 \times 8^{15} / 16$ in. $(17.8 \times 22.7 \mathrm{~cm})$. The Metropolitan Museum of Art, Gift of James Van Der Zee Institute, 1970 (1970.539.30)

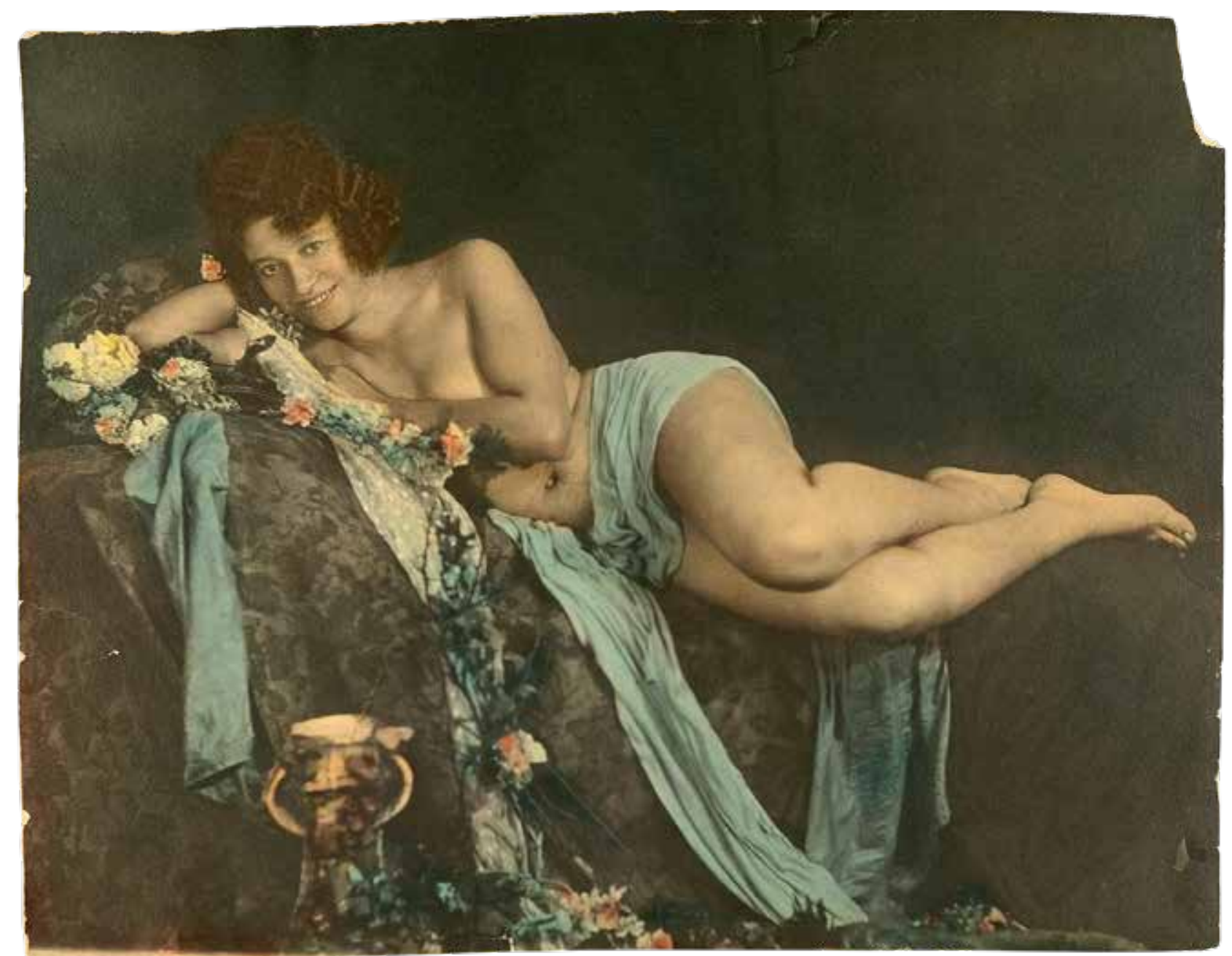

objects that, at first viewing, have no direct correlation to Black life. As the art historian Huey Copeland argues, Simpson's frustration with her artwork being interpreted as analogous to the social or political lives of Black individuals informed her "figurative retreat."46 Understanding the reasoning behind Simpson's omissions lends itself to thinking in parallel ways about Van Der Zee's images. Instead of considering the social lives of his subjects, what if the nuances of each photograph's materiality, its relationship to abstract forms, and its haptic qualities took center stage? ${ }^{47}$ Through Simpson's reframing, Van Der Zee's photographs can also be read through an attempt to retreat from the figure and an embrace of imaginative evocations of gesture, touch, and shape.

In "Reclining nude," Simpson does something distinct. Though the figure is still physically absent, the title and text connect to the overarching interest in the female body within Simpson's larger oeuvre. As Jones emphasizes in writing about Simpson's turn away from the Black figure, "for decades [African American] artists found it difficult to describe the nude black female visually. After centuries of rape and abuse under slavery, even the erotics of personal pleasure were hard to imagine." ${ }^{48}$ In its place, Simpson represents the reclining nude through the image of a tall vase with a rounded bottom and an upper section that angles outward like an extended crown. Below it, she offers this description:

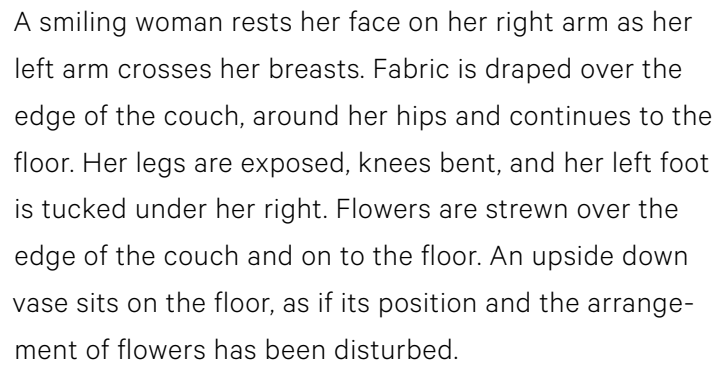

From this text the viewer can recreate an intimate scene of a woman comfortably posing with a smile across her face. Importantly, Simpson carefully separates the description of the more chaotically arranged props from that of the serene nude. Given the rarity of early twentieth-century photographs of the Black nude body 
fig. 10 Lorna Simpson. Upside Down, Right Side Up, 1993. Photo on linen panel, 2 panels, overall: $52 \times 41$ in. $(132.1 \times 104.1 \mathrm{~cm})$
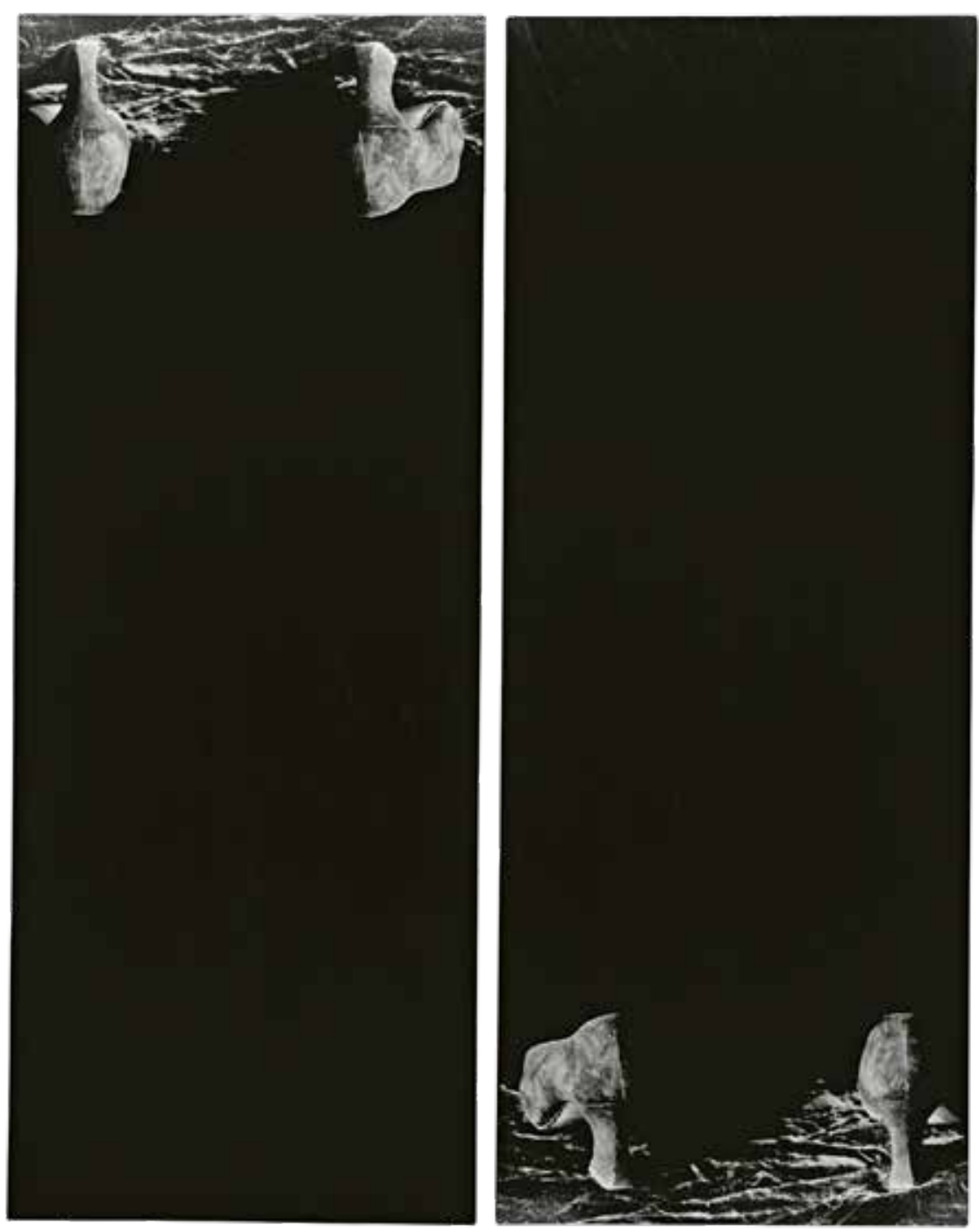

in affirmative representations, Van Der Zee's photograph reveals the unlikely kinds of visuality that existed and thrived before the Black photographer's camera during the Harlem Renaissance era (fig. 9). Moreover, with the body described as resting, bending, and sitting, the photograph becomes more than a historically exceptional example. Instead, through 9 Props, Simpson seems to suggest that the extraordinary aspects of Van Der Zee's nude photograph are the representational possibilities he offers not to the subject but to the viewer as an occasion to linger on provocations of line, movement, touch, and sight.

Simpson's composition in "Reclining nude" also provides the viewer with an additional alternative vantage point. First, this panel is the only one in 9 Props that does not feature a near exact replica of one of Van Der Zee's props: the vase is missing the sturdy arms that grace the sides of Van Der Zee's corresponding vase. Second, the vase appears in Van Der Zee's photograph, and is described, counter to the one in the panel, as an upside-down object, echoing the arrangement of the heeled shoes in Simpson's two-panel work from 1993Upside Down, Right Side Up (fig. 10). As Simpson explains, the significance of this positioning of objects is indebted to the historical depictions of the body: "In Western art the representation of a figure upside down is death. So this is about absence of someone missingthat double absence of death." ${ }^{49}$ While images of Saint Peter crucified head-down support Simpson's statement about Western art and death, this quotation more importantly illustrates the expansive ways Simpson explores themes of absence throughout her larger body of work and brings these relational reflections on Van Der Zee to the fore.

Describing the vase as upside down but featuring it as right side up may also remind the viewer of Simpson's propensity toward the unconventional backward positioning of the Black female body. By depicting Black 
fig. 11 James Van Der Zee. Beau of the Ball, 1926. Gelatin silver print. Collection of Donna Mussenden Van Der Zee

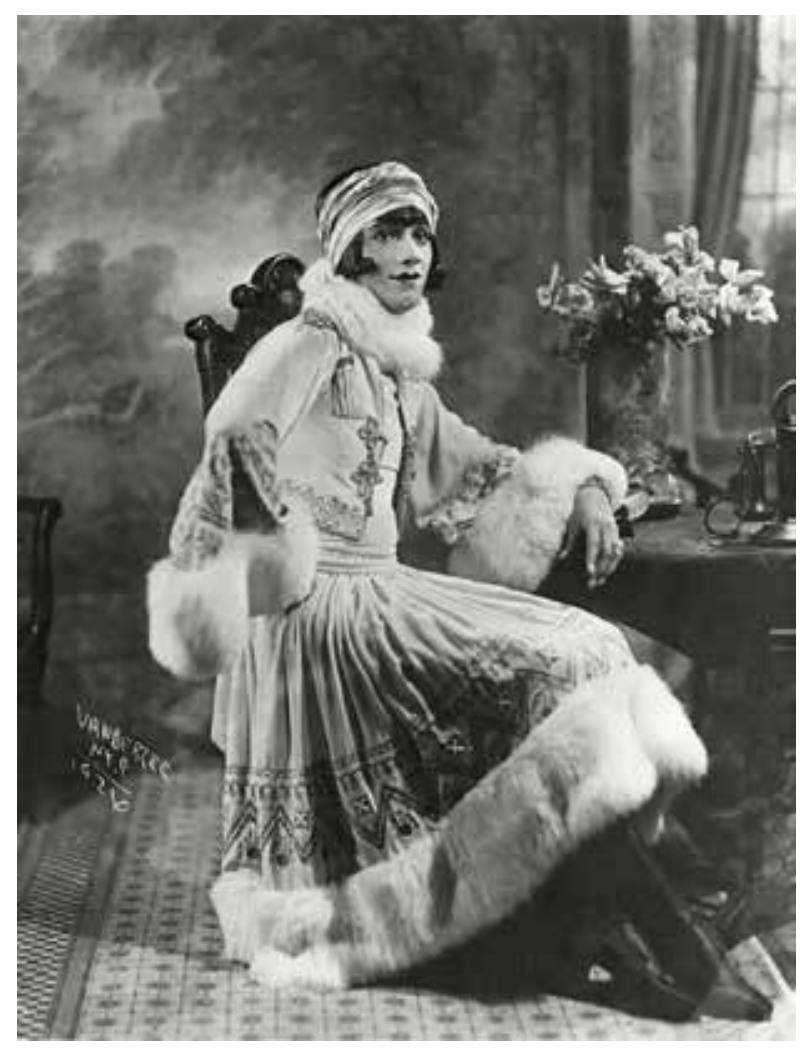

women from behind, Simpson invites the viewer to look at women from a certain vantage point. This compositional device disrupts normalized patterns of viewing and offers another angle or approach. The backward figures serve the same purpose as the upside-down vase described in "Reclining nude." 9 Props encourages viewers to approach Van Der Zee by sidestepping his subjects, gestures that make it difficult to engage with the existing historiography surrounding the photographer forever linked to the Harlem Renaissance era. To read Simpson's 9 Props as a kind of source material that supports and extends the history of Van Der Zee in a different direction is to offer a powerful interpretative framework supported by one's imagination. As Simpson references larger themes that thread throughout her oeuvre, she gives the viewer an opportunity to begin to recast Van Der Zee's work as well.

\section{A DUET}

At a lecture given in 2010, Simpson highlighted the importance of her own biography to her creation of 9 Props. Presenting before a slide of Van Der Zee's Beau of the Ball (fig. 11), she recalled that both her parents had cameras, which she was allowed to hold but not to use. She then explained how she acquired her first camera as a child: "I remember cutting out coupons on the back of the Kleenex boxes to get a Polaroid camera. Since I had a cold I had enough boxes to get a camera which I later got that spring and I had that camera everywhere." ${ }^{50}$ This experience has notable parallels with Van Der Zee's own account of how he obtained his first camera: after coming upon an advertisement that promised a camera as a prize for selling packets of lady's powder, he successfully sold the required amount and was rewarded with a camera, a few glass plates, and chemicals for developing. ${ }^{51}$

Although Van Der Zee's experience preceded Simpson's by nearly a century, she seems to have intentionally told this story in order to frame her artwork through her engagement with Van Der Zee's biography as a photographer. As Simpson writes on her artistic practice more generally, "When presented with the opportunity to provide my own writing on the inner workings or the events behind the scenes of my work, I find that the elements that stand out the most are the anecdotal and coincidental moments that have perforated the plans I had originally envisioned." ${ }^{2}$ In this case, the coincidental moment pays dividends in terms of putting Simpson and Van Der Zee in conversation across time in ways that cannot be gleaned from just looking at their work. In short, she uses the genre of biography to create a mirrored narrative.

In fact, to address two artists and their extensive engagement with photographs resonates with Simpson's own description of 9 Props as an homage. As suggested by the phrase "to give props," an homage acknowledges the worth and value of another person. To let this concept of a "prop" take the lead reinforces how Simpson's work can push the boundaries of historical knowledge and specificity while handing the interpretation over to the viewer to follow whatever imagining 9 Props may elicit. ${ }^{53}$ With its exchange of forms between Simpson and the gaffers, Simpson and the printers at 21 Steps, and most notably Simpson and Van Der Zee, 9 Props is built on a duet between collaborators. ${ }^{54}$ The viewer, standing before 9 Props, becomes an added interlocutor within the work's lineage. Through a range of textual details, visual forms, and supporting clues, the viewer is forced to labor over the experience of seeing 9 Props in order to imagine on their own terms. Such an engagement means that the narrative surrounding 9 Props is always being amended, even when these imaginative musings are absent from art's published history.

\section{EMILIE BOONE}

Assistant Professor of Art History, African American Studies Department, CUNY, New York City College of Technology 
1 Schoener 1969; Cooks 2011, pp. 53-86; Cahan 2016, pp. 31-108.

2 For example, art historian Huey Copeland (2013, p. 65) uses the term "antiportrait" to define an aesthetic style common to this and other works by Simpson. See also the MMA online catalogue entry for 9 Props, https://www.metmuseum.org/art /collection/search/490687; Villaseñor 1996, pp. 73, 74; and Eckrich 2014.

3 Smith 2020b, p. 92

4 Ibid., pp. 92, 103. Additionally, Smith argues that 9 Props "gives props" to Van Der Zee and his visions of Black futurity and the future worlds Van Der Zee and his subjects conjured. Ibid., p. 92.

5 "Becoming" is a reference to Stuart Hall's well-known use of the term. According to Hall, cultural identities are constantly undergoing transformations through instances of "becoming" as well as of "being." Hall 1990, p. 225.

6 Flusser 2005, p. 25. To situate Flusser within the larger discourse on imagination and photography, see Morris-Reich and Olin 2020, p. xix.

7 Blair 2007, p. 255.

8 See Campt 2012, p. 5.

9 Scholarship on photography and imagination includes a range of topics such as spirit photography and other intentionally modified, fictional photographs. In this article, imagination is what one does with one's eyes closed when one is not seeing. MorrisReich and Olin 2020, p. xvi. Such a definition aligns with Smith's use of the term when considering 9 Props; Smith 2020a, p. 134 My use of the term imagination is also informed by Kara Keeling's writing on the Black radical imagination as defined as "work(ing) with and through what exists in order to call forth something presently absent: a new relationship between and within matter." Keeling 2019, p. 34. For a succinct summary on the black radical imagination, see ibid., pp. 34-36.

10 Blair 2007, p. 253.

11 Ozelle 1994, p. 11.

12 The nine Van Der Zee photographs referenced in 9 Props are (from top left) Woman with a Goldfish Bowl, 1923; Beau of the Ball, 1926; Benny Andrews, 1976; A Man in His Bedroom, 1931; Dinner Party with Boxer Harry Wills, 1926; Reclining Nude, 1920s-40s; Just Before the Battle, 1920s; Max Robinson, 1981; and, lastly, Tea Time at Madame C. J. Walker's Beauty Salon, 1929. The MMA has prints of Dinner Party with Boxer Harry Wills, Reclining Nude, and Tea Time at Madame C. J. Walker's Beauty Salon.

13 Simpson 2010

14 Willis and Birt 1993.

15 Simpson 2010.

16 See the 1996 program catalogue of the Pilchuck Glass School, Stanwood, Washington. Both Morris and Marioni are established glass artists. Three works by Morris are in the Met's collection (MMA 1994.386a-d; 1995.221.1a, b; 1995.221.2a, b).

17 Smith 2020b, p. 94.

18 See Jones 2002, p. 63. One of the panels appeared printed as a photolithograph, Van Der Zee Prop Vase (1994), as part of a fourteen-piece portfolio of works produced by the Whitney for the 1993 Whitney Biennial in Seoul; Whitney Museum of American Art (96.59.12; https://whitney.org/collection /works/10398).

19 Simpson 2010

20 Ibid.

21 The studio on 135th Street was the first of four successive studios that Van Der Zee operated in Harlem.
22 Scholars have yet to critically consider the props found in Van Der Zee's photographs. Other attributes within his photographs' composition are often privileged. For example, Victoria A.-T. Sancho has written about the tactile surface of his photographs and how his employment of double exposures has carried him beyond the use of props; Sancho 1998, p. 56. See also Birt 1989, p. 39.

23 Willis and Birt 1993, p. 69.

24 For a definition, see http://www.oxforddictionaries.com/us /definition/american_english/prop (accessed Oct. 1, 2016)

25 For example, Charlie Ahearn insists that "Nas's 'Genesis' was like a voice crying out in the desert; almost nobody was giving props to the pioneers back then, and I feel the track helped spark curiosity in the minds of the youth as to the origins of this thing we call hip-hop." Dyson and Daulatzai 2010, p. 262.

26 Villaseñor 1996, p. 75.

27 Morrison credits a funerary photograph by Van Der Zee and the photographer's description of the circumstances surrounding the death as early influences for her novel Jazz (1992); Gillespie 2008 , p. 78. For the referenced photograph, and its description, see Van Der Zee, Dodson, and Billops 1978, p. 84. In Daughters of the Dust (1991), Dash employs the cinematic device of a layered dissolve as a conscious tribute to Van Der Zee's practice of superimposing images in some of his photographs; Pidduck 2004 , p. 113. Julien claims that the mise-en-scène style in his film Looking for Langston (1989) is indebted to Van Der Zee's photographs; Julien 2013, p. 48.

28 Jean-Michel Basquiat (American, 1960-1988). VNDRZ, 1982. Acrylic and oil paint stick on canvas, $597 \% \times 30$ in. (152 $\times$ $76.2 \mathrm{~cm}$ ). Private collection.

29 Enwezor 1996, p. 52.

30 Robinson 1996, p. 35.

31 Simpson's intended ordering and display of the nine panels are in the 2019 guidelines in the object file for 1998.456.5a-j, Department of Modern and Contemporary Art, MMA.

32 As Enwezor writes, "her work pushes the boundaries of historical knowledge and specificity." Enwezor 1996, p. 51.

33 Willis and Birt 1993, p. 8.

34 For example, in "Frames of Mind," Lucy Lippard notes how the ways in which props support a narrative are often dependent upon the deletion or subtraction of information. Along similar lines, she explains that a prop serves to efface or envelop the actual self. Lippard 1997, unpaginated. For an alternate way of thinking about the photographer as prop within a Cameroonian context, see Zeitlyn 2010.

35 Barthes 1981, p. 13.

36 Benjamin 1999, p. 515.

37 “Lorna Simpson: Gathered," Brooklyn Museum, 2011, https://www.brooklynmuseum.org/exhibitions/lorna_simpson/. See also Morris 2011.

38 Lippard 1997, unpaginated.

39 Schwartz 2014, p. 9.

40 Copeland 2014, pp. 26-27.

41 Jones 2002, p. 68.

42 Belisle 2011, p. 157; Golden 2002, p. 16.

43 Jones 2002 , p. 68

44 Ibid., p. 63.

45 This phrase was first used in a conversation between curator Thelma Golden and Kellie Jones mentioned in Golden 1994, unpaginated. See also Copeland 2005. 
46 Jones 2002 , p. 80 . "Figurative retreat" is a term used by Copeland (2005) to describe Simpson's absenting of the Black female figure.

47 Campt 2017, p. 9.

48 Jones 2002, p. 69. Also see Powell 1997, p. 146.

49 Wilkes 1993, p. 20.

50 Simpson 2010. Simpson also describes her first camera in a conversation with Joan Simon (2013, p. 183).

51 Willis and Birt 1993, p. 30.

52 Simpson in Jones, Golden, and Iles 2002, p. 136.

53 Enwezor 1996, p. 51.

54 I thank Jennifer Farrell and Liz Zanis of the Met's Department of Drawings and Prints for framing the process of printmaking as an active collaboration between an artist and a printer.

\section{REFERENCES}

\section{Barthes, Roland}

1981 Camera Lucida: Reflections on Photography. Translated by Richard Howard. New York: Hill and Wang.

Belisle, Brooke

2011 "Felt Surface, Visible Image: Lorna Simpson's

Photography and the Embodiment of Appearance." Photography \& Culture 4, no. 2 (July), pp. 157-78.

Benjamin, Walter

1999 Selected Writings. Vol. 2, 1927-1934. Translated by Rodney Livingstone et al.; edited by Michael W. Jennings, Howard Eiland, and Gary Smith. Cambridge, Mass.: Harvard University Press.

Birt, Rodger C

1989 "For the Record: James Van Der Zee, Marcus Garvey, and the Unia Photographs." International Review of African American Art 8, pp. 39-48.

Blair, Sara

2007 Harlem Crossroads: Black Writers and the Photograph in the Twentieth Century. Princeton: Princeton University Press.

Cahan, Susan E.

2016 Mounting Frustration: The Art Museum in the Age of Black Power. Durham, N.C.: Duke University Press.

Campt, Tina M.

2012 Image Matters: Archive, Photography, and the African Diaspora in Europe. Durham, N.C.: Duke University Press. 2017 Listening to Images. Durham, N.C.: Duke University Press. Cooks, Bridget R.

2011 Exhibiting Blackness: African Americans and the American Art Museum. Amherst: University of Massachusetts Press.

Copeland, Huey

2005 “'Bye, Bye Black Girl': Lorna Simpson's Figurative Retreat." Art Journal 64, no. 2 (Summer), pp. 62-77.

2013 Bound to Appear: Art, Slavery, and the Site of Blackness in Multicultural America. Chicago: University of Chicago Press.

2014 "Unfinished Business as Usual: African American Artists, New York Museums, and the 1990s." In Come As You Are: Art of the 1990s, edited by Alexandra Schwartz, pp. 25-32. Exh. cat. Montclair: Montclair Art Museum.
Dyson, Michael E., and Sohail Daulatzai, eds.

2010 Born to Use Mics: Reading Nas's IIImatic. New York: Basic Civitas Books.

Eckrich, Kristen

2014 “Lorna Simpson's 9 Props: Deconstructing Photographic Portraiture." M.A. thesis, American University, Washington, D.C. Enwezor, Okwui

1996 "Social Grace: The Work of Lorna Simpson." Third Text: Third World Perspectives on Contemporary Art and Culture 10, no. 35, pp. 43-58.

Flusser, Vilém

2005 Towards a Philosophy of Photography. Translated by Anthony Mathews. London: Reaktion Books.

Gillespie, Carmen

2008 Critical Companion to Toni Morrison: A Literary Reference to Her Life and Work. New York: Facts on File.

Golden, Thelma

1994 “An Interview with Lorna Simpson." In Simpson 1994, unpaginated.

2002 "Interview: Thelma Golden in Conversation with Lorna Simpson." In Jones, Golden, and Iles 2002, pp. 6-25.

Hall, Stuart

1990 "Cultural Identity and Diaspora." In Identity: Community, Culture, Difference, edited by Jonathan Rutherford, pp. 222-37. London: Lawrence \& Wishart.

Jones, Kellie

2002 "Off the Wall and (Back) Into the World." In Jones, Golden, and Iles 2002, pp. 63-83.

Jones, Kellie, Thelma Golden, and Chrissie lles

2002 Lorna Simpson. London: Phaidon.

Julien, Isaac

2013 Isaac Julien: Riot. New York: Museum of Modern Art.

Keeling, Kara

2019 Queer Times, Black Futures. New York: New York University Press.

Lippard, Lucy

1997 "Frames of Mind." In "From the Background to the Foreground: The Photo Backdrop and Cultural Expression," Afterimage 24, no. 5 (March-April), unpaginated.

Morris, Catherine J.

2011 Lorna Simpson: Gathered. Press release. Electronic ed., http://www.brooklynmuseum.org/opencollection/exhibitions /3228/Lorna_Simpson\%3A_Gathered.

Morris-Reich, Amos, and Margaret R. Olin

2020 "Introduction." In Photography and Imagination, edited by Amos Morris-Reich and Margaret Olin, pp. xiv-xxiv. New York: Routledge.

Ozelle, Vida

1994 "A Brief Guide to Siligraphy (Waterless Lithography)." In Hot Off the Press: Politics \& Prints, edited by Linda Tyler and Barry Walker, pp. 117-32. Albuquerque: Published for Tamarind Institute by the University of New Mexico Press.

Pidduck, Julianne

2004 Contemporary Costume Film: Space, Place and the Past. London: BFI.

Powell, Richard J.

1997 Black Art and Culture in the 20th Century. New York: Thames and Hudson.

Robinson, Jontyle Theresa

1996 "Passages." In Jontyle Theresa Robinson et al., Bearing Witness: Contemporary Works by African American Women Artists, 
pp. 15-37. Exh. cat., Spelman College, Atlanta, Ga.; Fort Wayne Museum of Art, 1997. New York: Spelman College and Rizzoli.

Sancho, Victoria A.-T

1998 "Respect and Representation: Dawoud Bey's Portraits of Individual Identity." Third Text: Third World Perspectives on Contemporary Art and Culture 12, no. 44, pp. 55-68.

Schoener, Allon, ed.

1969 Harlem on My Mind: Cultural Capital of Black America 1900-1968. Preface by Thomas P. F. Hoving; introduction by Candice Van Ellison. New York: Random House.

Schwartz, Alexandra

2014 "Chaotic Input: Art in the United States, 1989-2001." In Come As You Are: Art of the 1990s, edited by Alexandra Schwartz, pp. 9-22. Exh. cat. Montclair: Montclair Art Museum. Simon, Joan

2013 Lorna Simpson. Foundation for the Exhibition of Photography, Minneapolis. Exh. cat., Jeu de Paume, Paris; Haus der Kunst, Munich; Addison Gallery of American Art, Andover, Mass. New York; Munich: DelMonico Books, Prestel.

Simpson, Lorna

1994 Lorna Simpson, Standing in the Water. Exh. cat. New York: Whitney Museum of American Art.

2010 "Artist Talk: Lorna Simpson," video, May 14. Minnesota: Walker Art Center. Electronic ed., http://www.walkerart.org /channel/2010/artist-talk-lorna-simpson.

Smith, Shawn Michelle

2020a "The Performative Index: James VanDerZee, Roland Barthes, Lorna Simpson, and the Photographic Imagination." In Photography and Imagination, pp. 133-46. New York: Routledge. 2020b Photographic Returns: Racial Justice and the Time of Photography. Durham, N.C.: Duke University Press.

Van Der Zee, James, Owen Dodson, and Camille Billops

1978 The Harlem Book of the Dead. Dobbs Ferry, N.Y.: Morgan $\&$ Morgan.

Villaseñor, Maria Christina

1996 “Lorna Simpson: 'Nine Props': An Interview and Art Portfolio." Paris Review 38 (Spring), pp. 72-86.

Wilkes, Andrew

1993 "Lorna Simpson." In "On Location-Studio Visits with Annie Liebovitz, Lorna Simpson, Susan Meiselas, Cindy Sherman, Adam Fuss, Joel-Peter Witkin, John Goodman," Aperture, no. 133 (Fall), pp. 14-23

Willis, Deborah, and Rodger C. Birt

1993 VanDerZee, Photographer, 1886-1983, by Deborah WillisBraithwaite; biographical essay by Rodger C. Birt. Exh. cat. National Portrait Gallery, Smithsonian Institution, Washington, D.C. New York: Abrams.

Zeitlyn, David

2010 "Photographic Props/The Photographer as Prop: The Many Faces of Jacques Tousselle." History and Anthropology 21, no. 4, pp. 453-77. 